Article

\title{
Three-Dimensional Finite Element Analysis of Maxillary Sinus Floor Augmentation with Optimal Positioning of a Bone Graft Block
}

\author{
Peter Schuller-Götzburg 1,*(D), Thomas Forte ${ }^{1,3}$, Werner Pomwenger ${ }^{2}$, Alexander Petutschnigg ${ }^{3}$, \\ Franz Watzinger ${ }^{4}$ and Karl Entacher ${ }^{2}$ \\ 1 Prosthetics, Biomechanics and Biomaterial Research, Paracelsus Medical University, Strubergasse 21, \\ A-5020 Salzburg, Austria; thomas.forte@fh-salzburg.ac.at \\ 2 Department of Information Technologies and System Management, Salzburg University of Applied Science, \\ Urstein Süd 1, A-5412 Puch, Austria; werner.pomwenger@fh-salzburg.ac.at (W.P.); \\ karl.entacher@fh-salzburg.ac.at (K.E.) \\ 3 Department of Forest Products Technology and Wood Construction, Salzburg University of Applied \\ Sciences, Markt 136a, A-5431 Kuchl, Austria; alexander.petutschnigg@fh-salzburg.ac.at \\ 4 Department of Maxillofacial Surgery, Landesklinikum St. Pölten-Lilienfeld, Probst-Führer-Str. 4, \\ A-3100 St. Pölten, Austria; franz.watzinger@stpoelten.lknoe.at \\ * Correspondence: peter.schuller-goetzburg@pmu.ac.at; Tel.: +43-676-5339832; Fax: +43-662-871124-20
}

Received: 3 January 2018; Accepted: 22 January 2018; Published: 23 January 2018

\begin{abstract}
Purpose: the aim of the computational 3D-finite element study is to evaluate the influence of an augmented sinus lift with additional inserted bone grafting. The bone graft block stabilizes the implant in conjunction with conventional bone augmentation. Two finite element models were applied: the real geometry based bone models and the simplified geometry models. The bone graft block was placed in three different positions. The implants were loaded first with an axial force and then with forces simulating laterotrusion and protrusion. This study examines whether the calculated stress behavior is symmetrical for both models. Having established a symmetry between the primary axis, the laterotrusion and protrusion behavior reduces calculation efforts, by simplifying the model. Material and Methods: a simplified U-shaped 3D finite element model of the molar region of the upper jaw and a more complex anatomical model of the left maxilla with less cortical bone were created. The bone graft block was placed in the maxillary sinus. Then the von Mises stress distribution was calculated and analyzed at three block positions: at contact with the sinus floor, in the middle of the implant helix and in the upper third of the implant. The two finite element models were then compared to simplify the modelling. Results: the position of the bone graft block significantly influences the magnitude of stress distribution. A bone graft block positioned in the upper third or middle of the implant reduces the quantity of stress compared to the reference model without a bone graft block. The low bone graft block position is clearly associated with lower stress distribution in compact bone. We registered no significant differences in stress in compact bone with regard to laterotrusion or protrusion. Conclusions: maximum values of von Mises stresses in compact bone can be reduced significantly by using a bone graft block. The reduction of stress is nearly the same for positions in the upper third and the middle of the implant. It is much more pronounced when the bone graft block is in the lower third of the implant near the sinus floor, which appeared to be the best position in the present study.
\end{abstract}

Keywords: sinus lift; bone grafting; finite element analysis; 3D modeling; dental implant 


\section{Introduction}

Finite element (FE) analysis is an engineering and mathematical tool for structural analysis of bone morphology, implants, and load transfer in order to optimize surgical methods, design, and the fixation of implants. Recent developments in the generation of finite element models, the quality of computed tomography (CT) imaging and segmentation algorithms, faster computers, and the accuracy of finite element modeling have greatly enhanced the simulation of the individual patient's anatomy $[1,2]$.

Successful dental implant rehabilitation of the molars in a partly edentulous or completely edentulous maxilla depends on the quantity and quality of available alveolar bone. Low bone height may result from several factors, such as alveolar bone resorption after tooth extraction, periodontal disease, pneumatization of the sinus, or sinus morphology. Conventional implant insertion may not be feasible in cases of bone thickness below 3 or $2 \mathrm{~mm}$. The patients may require bone augmentation procedures. Sinus lift with elevation of the Schneiderian membrane and augmentation of the subantral space are commonly used in this setting [3,4].

As sufficient primary stability could not be achieved in patients with alveolar bone less than $2 \mathrm{~mm}$ thick, we used a modified procedure in these cases. A cortical bone graft block from the retromolar region of the mandible was inserted into the sinus during sinus lift augmentation from a lateral window, using granulated autogenous/xenogenous bone material. The bone graft block was anchored with two fixations screws (Figure 1). The latter permitted placement of the bone graft block in different positions in the sinus. The screws can be removed after four months; the screw holes serve as guidance for the insertion of dental implants. The method involves a two-step procedure: The first is augmentation while the second is the insertion of the implants after four months [5].

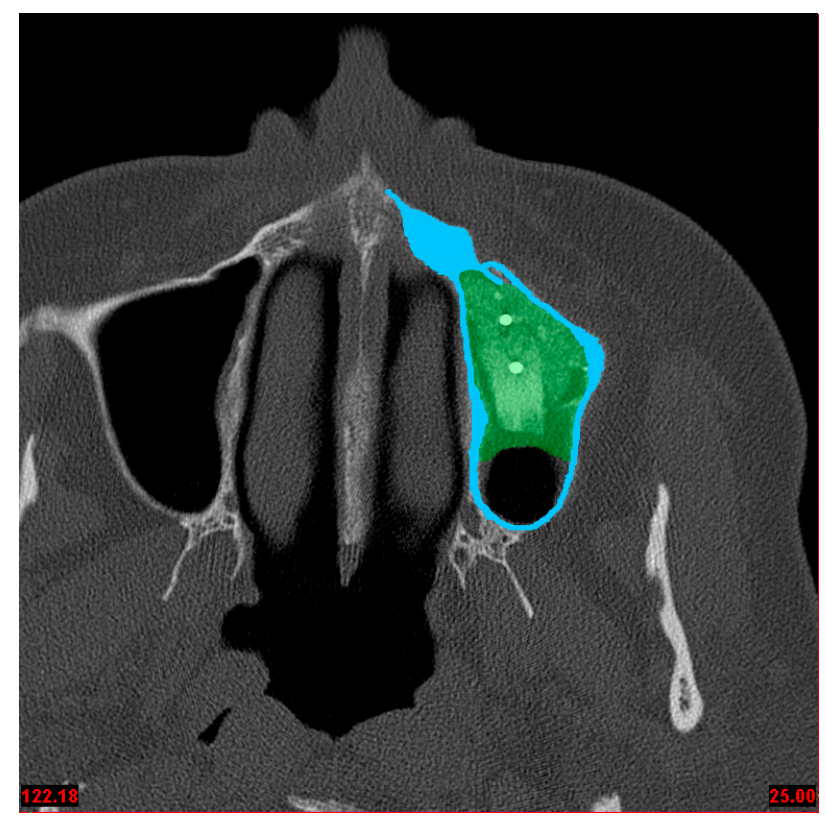

Figure 1. CT of the augmented left maxillary sinus with two fixing screws and the bone graft block. Blue indicates segmented compact bone; green indicates segmented augmented bone.

The procedure provides double anchorage of the implants in crestal bone and the cortical bone graft block [6,7], thus ensuring ideal stabilization and fixation of the implants and better integration of the implants into bone. It also minimizes loss rates during post-surgical implant healing.

The aim of the present study was to evaluate the different positions of the bone graft block with regard to the stability of the implants in the augmented maxillary sinus, using 3D-FE models. We investigated the implants in the healing phase and after osseointegration. 
The results of FE analysis depend significantly on the complexity and quality of the underlying models. One of the aims of the study was to analyze whether complex anatomical models are necessary or whether simplified 3D FE models are sufficient to obtain answers to the main questions of the study. Does one need to design an anatomical model? Two models-a simplified 3D U-shaped FE model and an anatomical 3D-FE model [8] —were generated to obtain results independent of geometric irregularities. The main purpose was to determine the most suitable position of the bone graft block with regard to compact bone, load directions as simulated by central, lateral and protrusive loading, and boundary conditions with a minimum of surrounding stresses. Three different positions of the bone graft block were studied.

\section{Material and Methods}

Finite element analyses were performed using two geometric models. M1 is a simplified U-shaped model with a compact bone thickness of $2 \mathrm{~mm}$ (Figure 2) while M2 is a 3D anatomical model based on CT data (Figure 3). Each model contains a bone graft block $(2.0 \times 6.0 \times 8.0 \mathrm{~mm})$ of compact bone with surrounding bone augmentation, and an implant of $4 \mathrm{~mm}$ diameter and $10 \mathrm{~mm}$ length (titanium grade 4, blueSky 4010, Bredent Medical, Senden, Germany). Three positions of the bone graft block were used: $2.60 \mathrm{~mm}, 5.27 \mathrm{~mm}$, and $7.93 \mathrm{~mm}$ from the implant neck.

A so-called reference model was analyzed additionally, omitting the bone graft in both geometric models (Table 1).

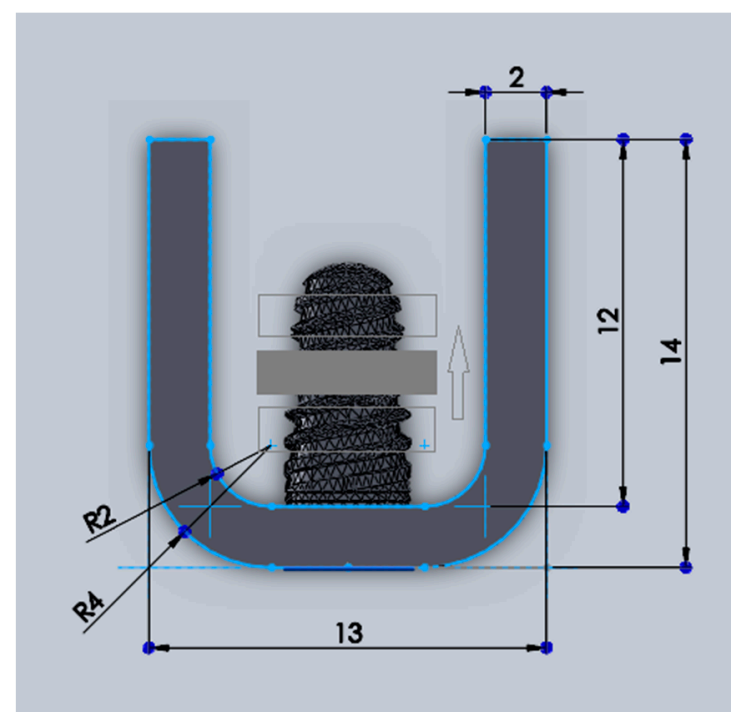

Figure 2. U-shaped 3D finite element (FE) model. The bone graft block is in the center of the dental implant, M1_c model (center position of the bone graft block). The different positions of the bone graft block are shown (illustrated).

Table 1. Twelve analyzed FE models.

\begin{tabular}{|c|c|c|c|c|c|}
\hline \multirow[b]{2}{*}{$\begin{array}{c}\text { Model } \\
\text { (Sub-Question 1) }\end{array}$} & \multicolumn{3}{|c|}{ Bone Graft Position (Main Question) } & \multirow[b]{2}{*}{$\begin{array}{l}\text { Reference } \\
\text { Model (r) }\end{array}$} & \multirow[b]{2}{*}{ Additional Information } \\
\hline & $\begin{array}{l}\text { on the } \\
\text { Top (t) }\end{array}$ & $\begin{array}{c}\text { in the } \\
\text { Center (c) }\end{array}$ & Below (b) & & \\
\hline \multirow{2}{*}{ M1 } & M1_t & M1_c & M1_b & M1_r & \multirow{2}{*}{$\begin{array}{c}\text { Compact bone } 2 \mathrm{~mm} \text { (osseointegrated phase) } \\
\text { Compact bone } 2 \mathrm{~mm} \text { with friction contact } \\
\text { (healing phase) }\end{array}$} \\
\hline & $\mathrm{M} 1_{\mathrm{f}-\mathrm{t}}$ & $\mathrm{M} 1_{\mathrm{f} \_\mathrm{c}}$ & $\mathrm{M} 1_{\mathrm{f}-\mathrm{b}}$ & $\mathrm{M} 1_{\mathrm{f} \_} \mathrm{r}$ & \\
\hline M2 & M2_t & M2_c & M2_b & M2_r & Model from CT data (osseointegrated phase) \\
\hline
\end{tabular}

M1: $2 \mathrm{~mm}$ compact bone thickness; M2: model based on CT data with variable compact bone thickness; $\mathrm{t}$ : top position of the bone graft; c: center position of the bone graft; b: lower position of the bone graft; r: reference model without a bone graft; $\mathrm{f}$ : ' $\mathrm{f}$ ' refers to friction contact between the implant and compact bone. 

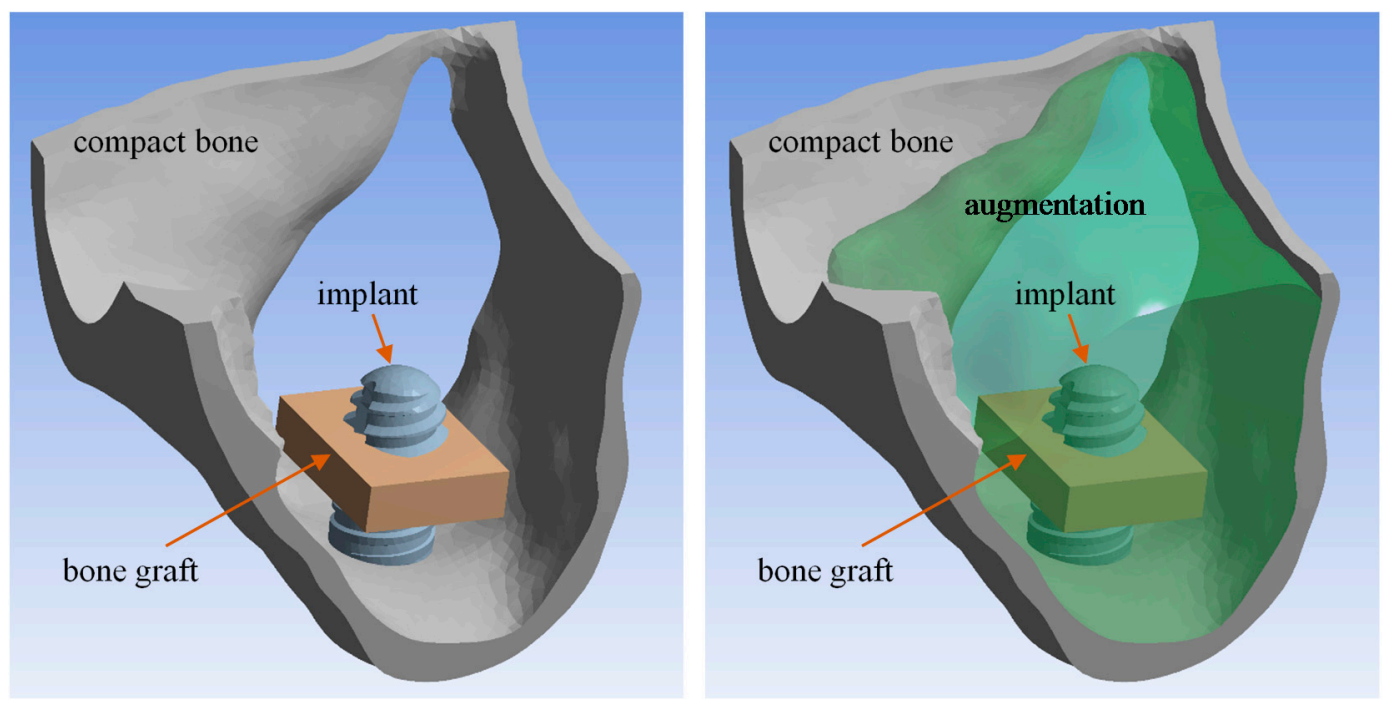

Figure 3. M2_c model-left: Compact bone, the implant and the bone graft in middle position; right: Compact bone with augmentation.

\section{Contact Definition}

Two types of contact between the implant and compact bone were used in the simplified M1 model. First, the contact between the implant and compact bone was bonded. This contact definition is used to simulate the osseointegrated state. Second, frictional contact (as in nature) with a friction coefficient of 0.3 was employed [9]. The friction coefficient was used according to previous studies [9]; it simulates the contact of the implant after insertion, at the beginning of the osseointegration process [10-12].

Young's modulus for cancellous bone and bone augmentation is $1.4 \mathrm{GPa}$; Poisson's ratio $\mu$ is 0.30. For cortical bone, compact bone and bone grafts, Young's modulus is $14 \mathrm{GPa}$ and Poisson's ratio $\mu=0.30$. For titanium alloy, Young's modulus is 103.4 GPa and Poisson's ratio $\mu=0.35$ [13].

The implant was loaded mechanically (masticatory, protrusive and laterotrusive load at abutment position), $9.0 \mathrm{~mm}$ away from the implant neck, at the level of crestal bone.

Loads applied on the dental implant at the end of the simplified abutment, as measured by Mericske-Stern [14] were as follows:

- $\quad \mathrm{F}_{\mathrm{z}}=96 \mathrm{~N}$ in the $\mathrm{z}$-axis representing masticatory force,

- $\quad \mathrm{P}_{\mathrm{y}}=36 \mathrm{~N}$ in the $\mathrm{y}$-axis presumed from protrusion, and

- $\quad \mathrm{L}_{\mathrm{x}}=13 \mathrm{~N}$ in the $\mathrm{x}$-axis from laterotrusion.

One load situation was defined for each load, as combinations can be easily calculated by superposition. This was done to analyze the effect of different bone graft positions on different load directions. The boundary conditions were defined as fixed supports in the cross-sectional areas of compact bone and augmentation - four surfaces in all—that constrain all vertical and translational degrees of freedom.

The software products 3-matic 5.1 (Materialise GmbH, Leuven, Belgium) and SolidWorks 2010 (Dassault Systèmes SolidWorks Corp., Munich, Germany) were used for 3D modeling, and the ANSYS 13.0 software (CADFEM GmbH, Vienna, Austria) for FE analysis. The FE model structure was meshed with 3D continuum tetrahedron elements. A local area net refinement around the shoulder of the implant was defined for meshing compact bone and augmentation. The number of nodes in compact bone were 41,700 in Model 1 and 88,400 in Model 2. 


\section{Results}

\subsection{Bone Graft Position}

(1) Equivalent von Mises stresses for compact bone

The diagrams in Figure 4 show cumulative distribution functions plots (CDF plots) of von Mises stress distribution values in compact bone, evaluated for masticatory force $F_{z}$ and protrusion load $\mathrm{P}_{\mathrm{y}}$ for the models M1 and M2. CDF plots serve as a simple method to visualize significant shifts in distribution. Principally the stresses should be below $20 \mathrm{MPa}$ because higher stresses cause resorption of the bone $[15,16]$. A shift of the CDF curve to the left indicates lower stresses in the augmented bone.

In comparison to Figure 4, the CDF plots for the models M1 and M2 with laterotrusion loading $\mathrm{L}_{\mathrm{x}}$ qualitatively show the same behavior as for protrusion loading.

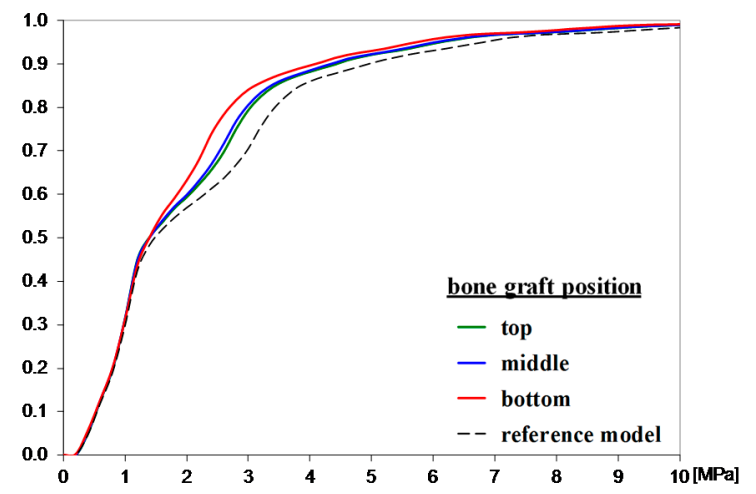

(a)

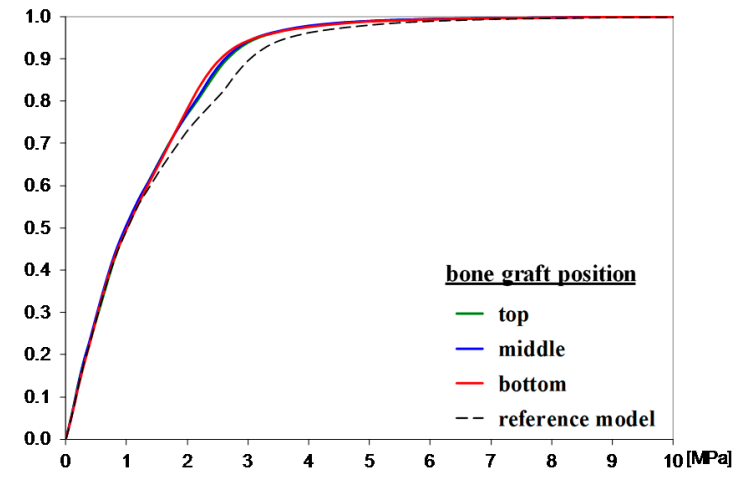

(c)

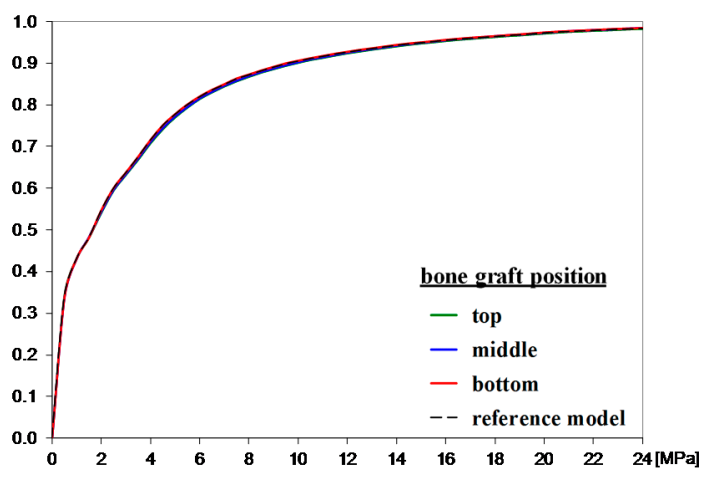

(b)

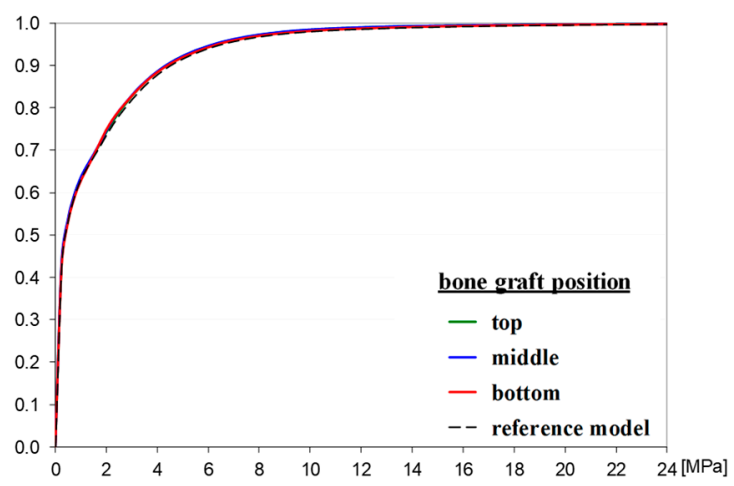

(d)

Figure 4. Cumulative distribution functions plots (CDF) plot of von Mises stress in compact bone for the M1 and M2 models; masticatory force Fz compared to protrusion load Py. Model M1, masticatory force $\mathrm{F}_{\mathrm{z}}(\mathbf{a})$; Model M1, protrusion $\mathrm{P}_{\mathrm{y}}(\mathbf{b})$; Model M2, masticatory force $\mathrm{F}_{\mathrm{z}}$ (c); Model M2, protrusion $\mathrm{P}_{\mathrm{y}}(\mathbf{d})$.

Model M1 - compact bone thickness $2 \mathrm{~mm}$ (Figure 2)

For masticatory force $\mathrm{F}_{\mathrm{z}}$, the lowest bone graft block position had the lowest von Mises stress distribution. The difference between the reference model and the M1 model is notable. In addition, there is a slight difference between the center and the top bone graft block position.

The analysis with loads of protrusion $\mathrm{P}_{\mathrm{y}}$ and laterotrusion $\mathrm{L}_{\mathrm{x}}$ revealed no significant differences with regard to the distribution of von Mises stress in compact bone due to the position of the bone graft block. Von Mises stresses were higher for $\mathrm{P}_{\mathrm{y}}$ and $\mathrm{L}_{\mathrm{x}}$ (up to $56.2 \mathrm{MPa}$ for $\mathrm{P}_{\mathrm{y}}$ and $19.4 \mathrm{MPa}$ for $\mathrm{L}_{\mathrm{x}}$ ) than for masticatory force $\mathrm{F}_{\mathrm{z}}(\max 15.3 \mathrm{MPa})$.

Model M2 - anatomical model with variable compact bone from CT data (Figures 1 and 3) 
For masticatory force $\mathrm{F}_{\mathrm{z}}$, placing the bone graft block in the lowest position again resulted in the lowest stress distribution for compact bone. Due to the more complex and larger geometry of compact bone-resulting in more numerous elements - the difference is not as significant as it is in the M1 model.

For $\mathrm{P}_{\mathrm{y}}$ (protrusion) and $\mathrm{L}_{\mathrm{x}}$ (laterotrusion), we again registered non-significant differences in the distribution of von Mises stress in compact bone due to the position of the bone graft block.

Figure 5 shows representative von Mises stresses for the M2_c model (bone graft block in the center of the implant) that result from masticatory force $\mathrm{F}_{\mathrm{z}}$ and protrusion load $\mathrm{P}_{\mathrm{y}}$. Maximum von Mises stresses occur in the lower part of compact bone for both loads. The stress values for $F_{z}$ are approximately three times lower than those for $P_{y}$. The differently scaled color plots in Figure 5 show a smaller red area for $\mathrm{F}_{\mathrm{z}}$, which signals stresses greater than $8 \mathrm{MPa}$ compared to $\mathrm{P}_{\mathrm{y}}$, where the red area represents stresses greater than $22 \mathrm{MPa}$. The M1 and M2 models show the same trends for $\mathrm{P}_{\mathrm{y}}$ and $\mathrm{L}_{\mathrm{x}}$.
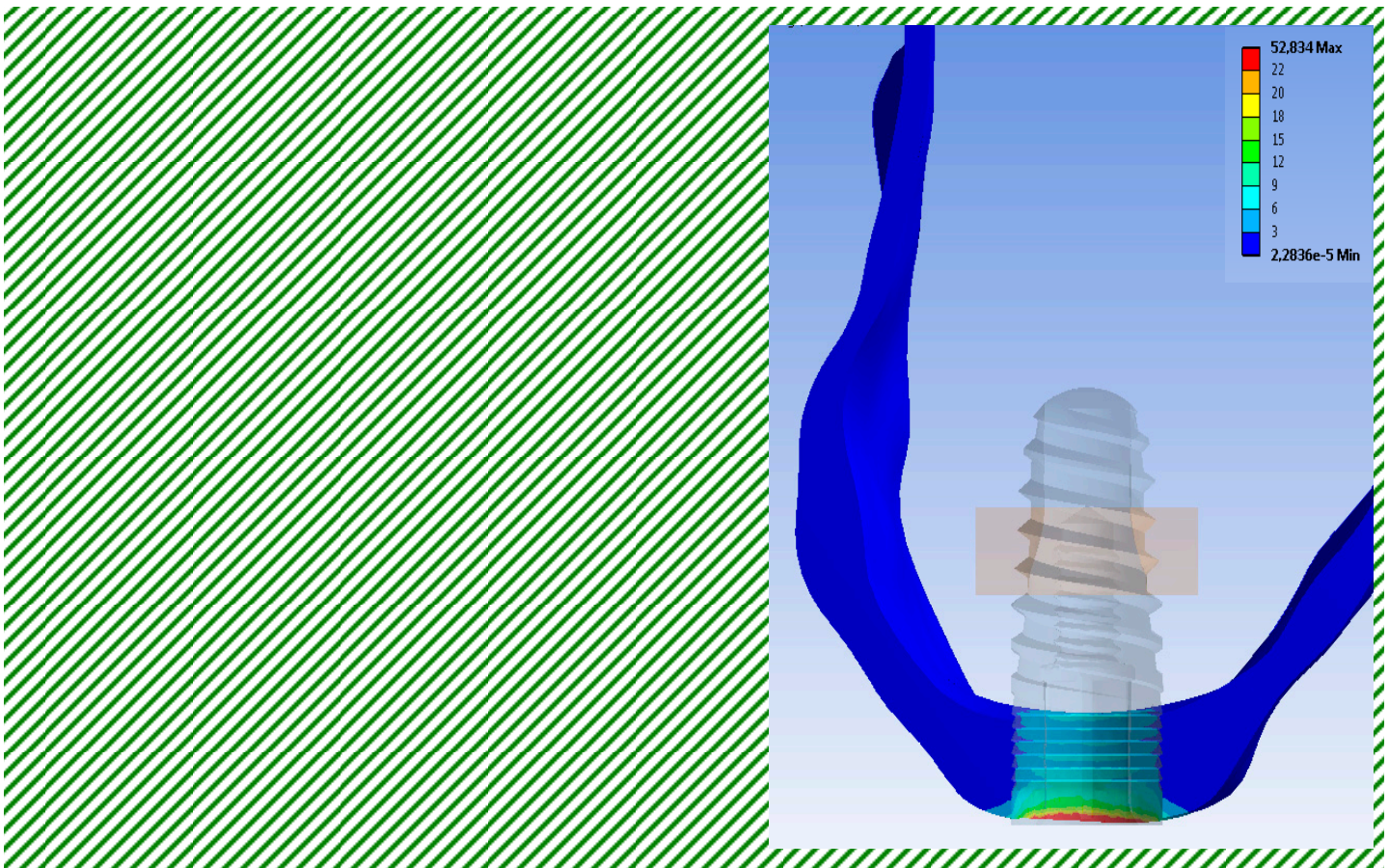

Figure 5. Von Mises stress [MPa] in compact bone in the M2_c model, with the bone graft positioned in the center; $\mathrm{F}_{\mathrm{z}}$ (masticatory force) on the left and $\mathrm{P}_{\mathrm{y}}$ (protrusion) on the right (augmentation as in Figure 2, but not shown here).

\section{(2) Strain energy in model M1—compact bone thickness of $2 \mathrm{~mm}$}

Subsequent strain energy in the bone graft block, in compact bone, the augmentation, and the implant are shown in the M1 model for masticatory load $\mathrm{F}_{\mathrm{z}}$ (Figure 6, Table 2) and for protrusion load $\mathrm{P}_{\mathrm{y}}$ (Figure 7, Table 3). For masticatory force $\mathrm{F}_{\mathrm{z}}$, the strain energy of compact bone is reduced because of the bone graft block compared to the reference model. This occurs relatively independent of bone graft block position. Furthermore, a low bone graft block position reduces strain density for the implant and the augmentation to a slight extent.

For protrusion load $\mathrm{P}_{\mathrm{y}}$, a low bone graft position is able to reduce the strain energy of compact bone in the M1_b model while the bone graft block achieves its highest strain energy. The augmentation shows similar ranges of strain energy, independent of the position of the bone graft block. The bone graft block and its position directly influence strain energy in compact bone for $\mathrm{P}_{\mathrm{y}}$ in the M1 model. The implant strain energy is slightly higher in the M1 model with the bone graft block on the top, and slightly lower in the M1 model with the bone graft block below, compared to the reference model 
without a bone graft block. There is a slight decrease in the strain energy of the implant in the M1_t model with the bone graft block on the top compared to the M1_b model with the low bone graft block position. Figures 6 and 7 show that the system turns stiffer in the presence of the bone graft block compared to the reference model for masticatory and protrusion loads $\mathrm{F}_{\mathrm{z}}$ and $\mathrm{P}_{\mathrm{y}}$.

The strain energy values of M1 are shown in Tables 2 and 3.

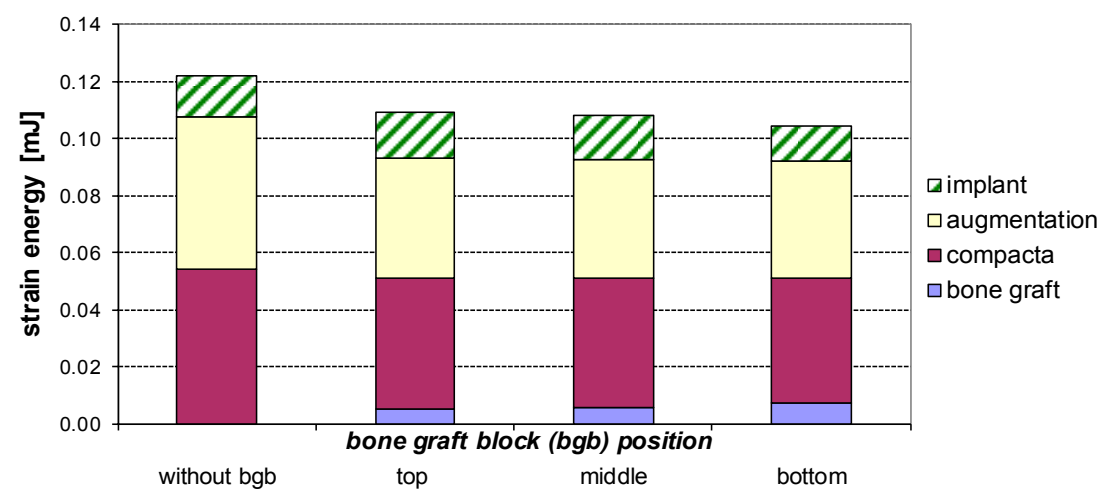

Figure 6. Strain energy in the M1 model, with $\mathrm{F}_{\mathrm{Z}}$ (masticatory force) applied.

Table 2. Strain energy in the M2 model, with $\mathrm{F}_{\mathrm{z}}$ (masticatory force) applied.

\begin{tabular}{cccccc}
\hline & M1_r & M1_t & M1_c & M1_b & \\
\hline Bone graft & & 0.005 & 0.006 & 0.007 & $\mathrm{~mJ}$ \\
Compact bone & 0.054 & 0.046 & 0.045 & 0.044 & $\mathrm{~mJ}$ \\
Augmentation & 0.053 & 0.042 & 0.042 & 0.041 & $\mathrm{~mJ}$ \\
Implant & 0.014 & 0.016 & 0.015 & 0.012 & $\mathrm{~mJ}$ \\
\hline
\end{tabular}

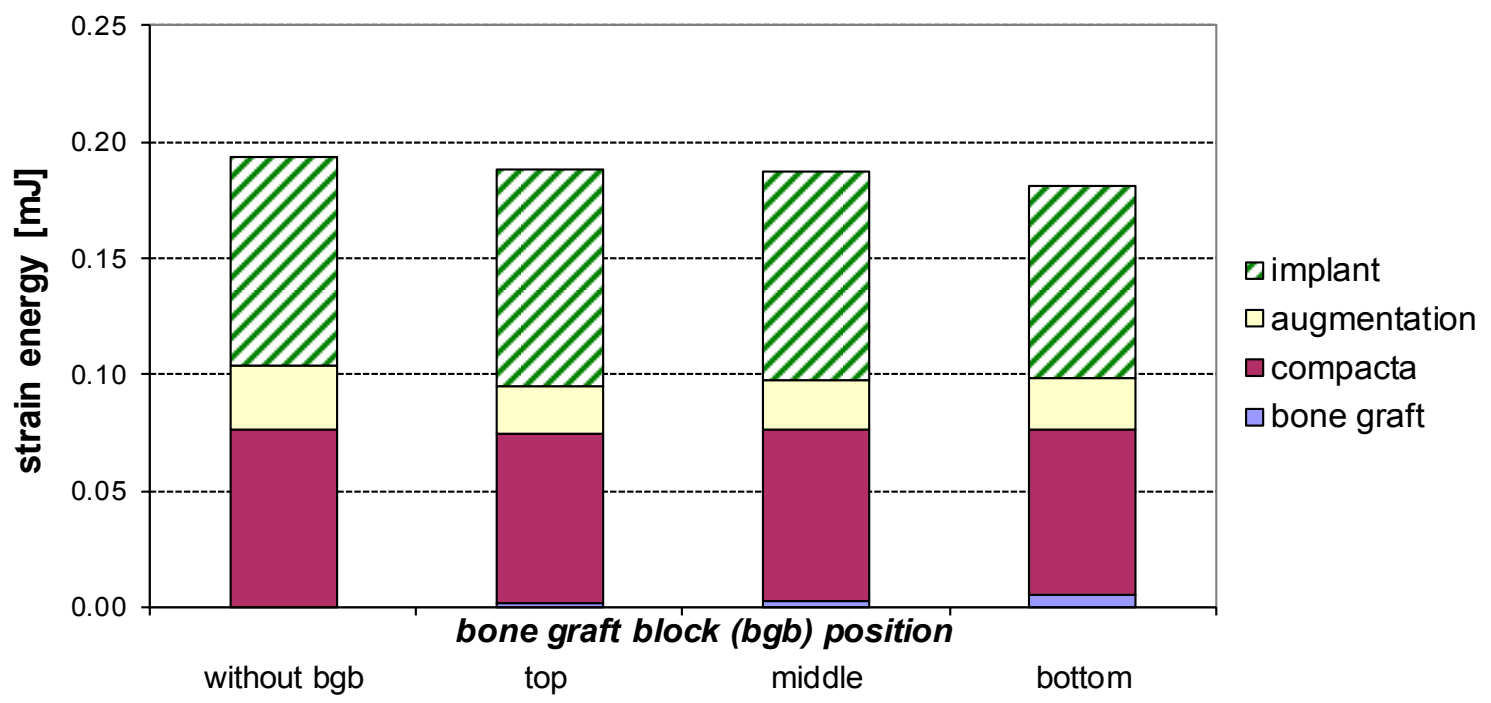

Figure 7. Strain energy in the M1 model, with $\mathrm{P}_{\mathrm{y}}$ (protrusion) applied.

Table 3. Strain energy in the M2 model, with $\mathrm{P}_{\mathrm{y}}$ (protrusion) applied.

\begin{tabular}{cccccc}
\hline & M1_r & M1_t & M1_c & M1_b & \\
\hline Bone graft & & 0.001 & 0.002 & 0.006 & $\mathrm{~mJ}$ \\
Compact bone & 0.077 & 0.073 & 0.074 & 0.070 & $\mathrm{~mJ}$ \\
Augmentation & 0.027 & 0.020 & 0.021 & 0.023 & $\mathrm{~mJ}$ \\
Implant & 0.090 & 0.094 & 0.090 & 0.083 & $\mathrm{~mJ}$ \\
\hline
\end{tabular}




\subsection{Consideration of the Friction Coefficient in Contact between the Implant and Compact Bone}

In the simplified M1 model, we defined a friction coefficient between the surfaces of the implant and compact bone in order to prevent high tensile stresses in this area. Further, the stress distribution is more realistic when using this contact definition, as shown in Figure 8.
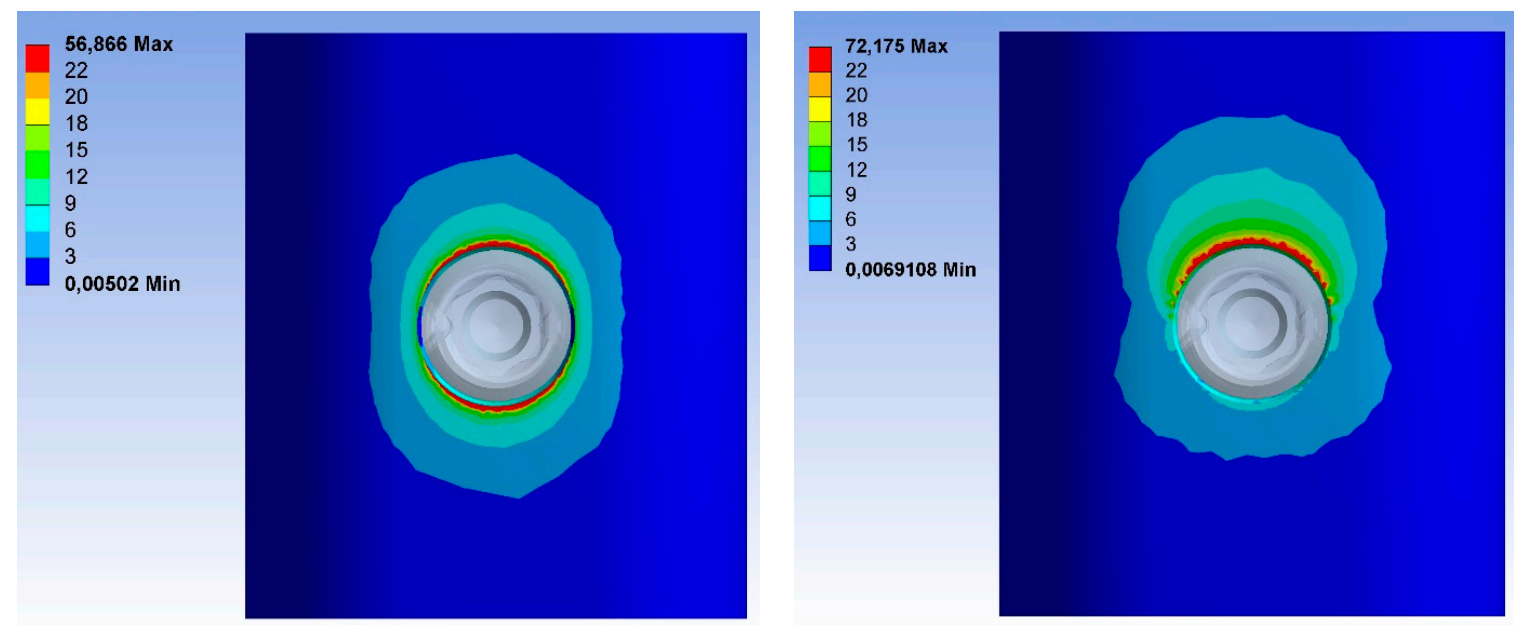

Figure 8. Von Mises stress distribution [MPa] in compact bone due to load $\mathrm{P}_{\mathrm{y}}$ (protrusion), as seen from below; left bonded contact M1_r and right friction contact $\mathrm{M} 1_{\mathrm{f} \_} \mathrm{r}$ between the implant and compact bone.

$\mathbf{M} 1_{\mathbf{f}}$-compact bone thickness of $2 \mathrm{~mm}$

The stress gradient in compact bone for $\mathrm{F}_{\mathrm{Z}}$ shows very similar behavior as it does in bonded contact, Figure 9. The consideration of a friction coefficient results in lower von Mises stresses in compact bone. An interesting difference is noted for $\mathrm{P}_{\mathrm{y}}$ compared to bonded contact. In terms of bone graft block position, there is a gradual reduction of von Mises stresses starting from the reference model $\mathrm{M}_{\mathrm{f}} \mathrm{r}$ without a bone graft block, to the top bone graft block position, to the center position, and finally to the low position in the $\mathrm{M1}_{\mathrm{f}-} \mathrm{b}$ model. Meanwhile, no difference was observed in the M1 model with bonded contact (Figure 4).

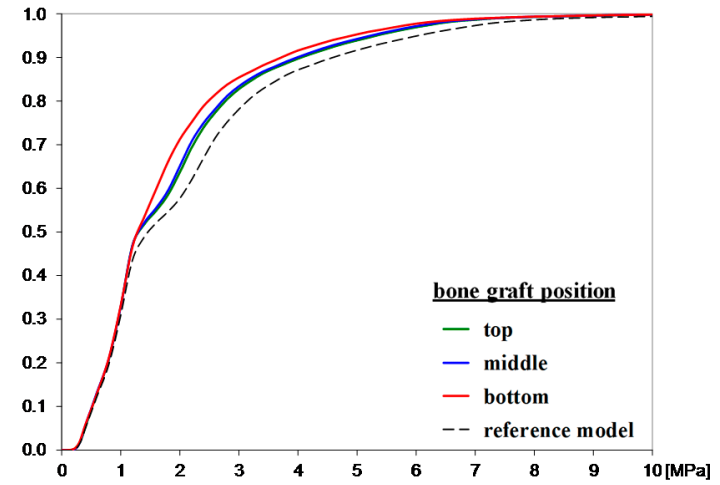

(a)

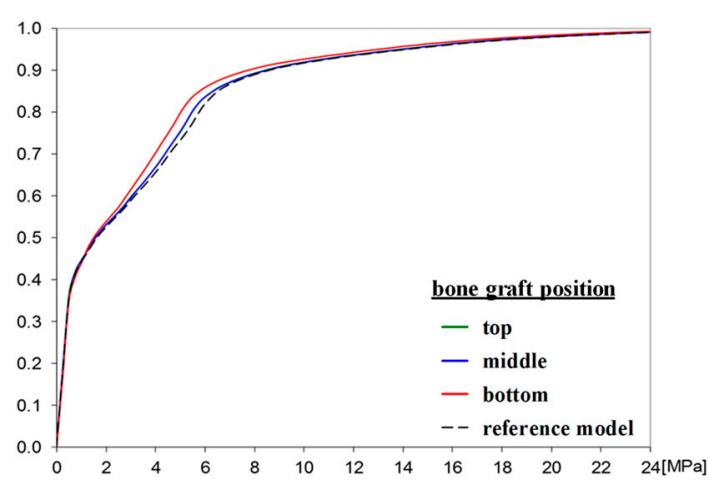

(b)

Figure 9. CDF plot of von Mises stress in $2 \mathrm{~mm}$ compact bone for the $\mathrm{M} 1_{\mathrm{f}}$ model, with friction and different loads applied. $\mathrm{M}_{\mathrm{f}}$ model with masticatory force $\mathrm{F}_{\mathrm{Z}}$ applied (a) and $\mathrm{M} 1_{\mathrm{f}}$ model with protrusion $\mathrm{P}_{\mathrm{y}}$ applied (b). 


\subsection{Strain Energy in the $M 1_{f}$ Model}

For masticatory force $\mathrm{F}_{\mathrm{z}}$, the strain energy distribution is similar in the bonded situation and under consideration of a defined friction coefficient (Figure 10). The strain energy of compact bone was reduced because of the bone graft block compared to the reference model, while different bone graft block positions did not influence the strain energy of compact bone. Furthermore, a low bone graft block position slightly reduced the strain density for the implant and the augmentation, but did not affect the strain energy of compact bone. Figure 10 shows that the system turns stiffer in the presence of the bone graft block compared to the reference model.

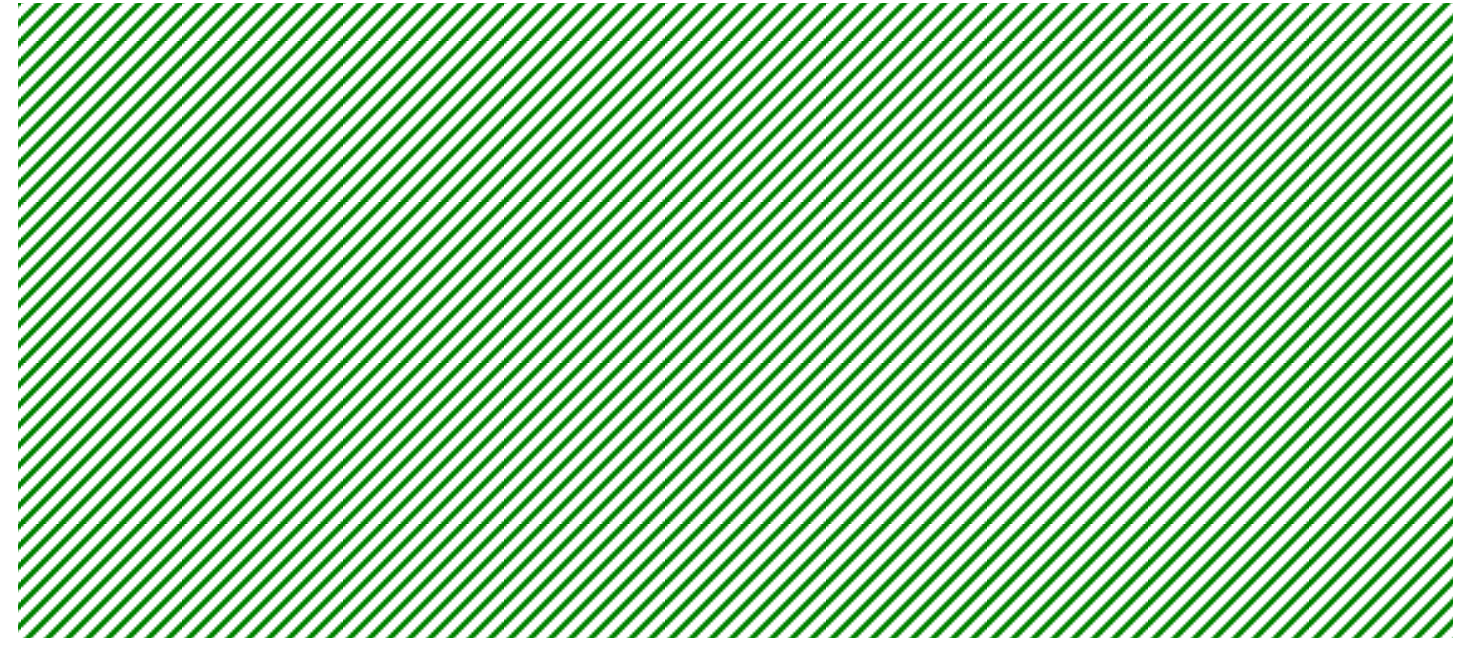

Figure 10. Strain energy in the $\mathrm{M} 1_{\mathrm{f}}$ model, with friction and $\mathrm{F}_{\mathrm{Z}}$ (masticatory force) applied.

When $P_{y}$ was applied, the overall strain energy was higher for a defined friction coefficient than it was for bonded contact (compare Figure 7 with Figure 11). In other words, for $\mathrm{P}_{\mathrm{y}}$ the $\mathrm{M} 1_{\mathrm{f}}$ system is less stiff when using the definition of a friction coefficient. Implant deformation does not increase due to the presence of the bone graft block.

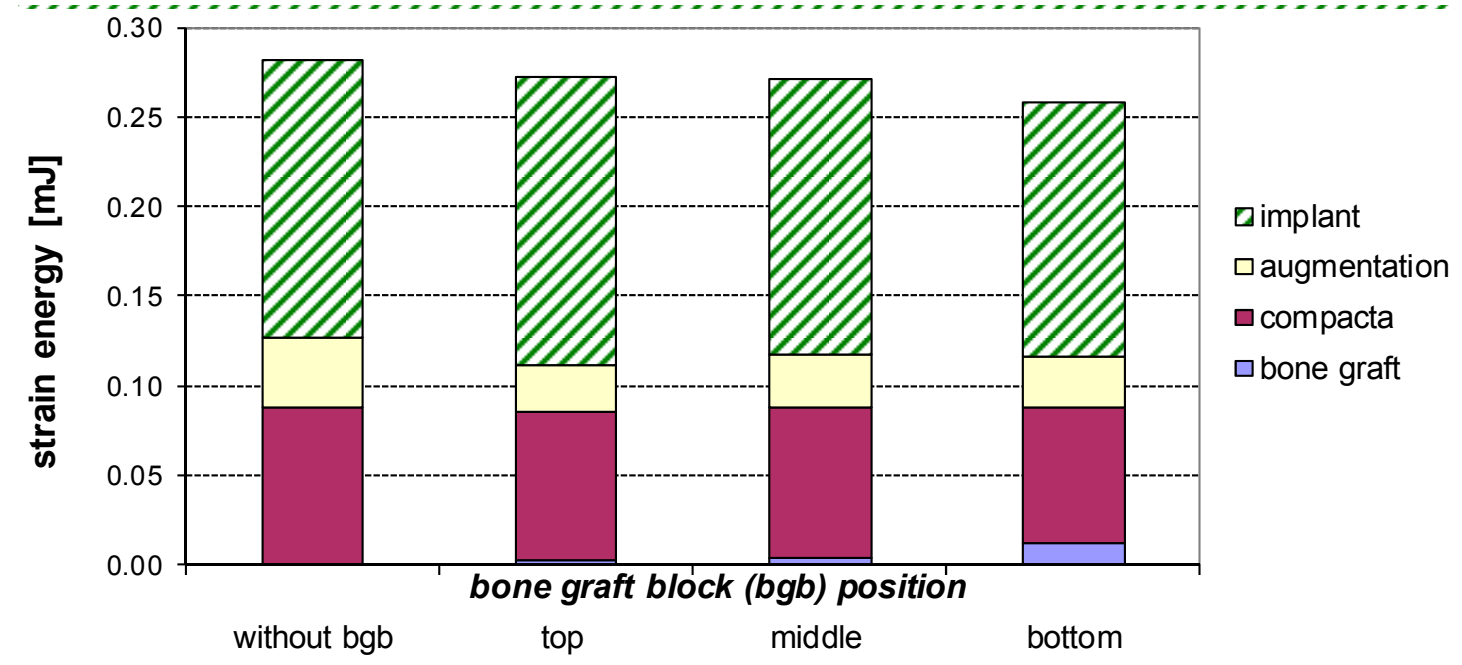

Figure 11. Strain energy in the $\mathrm{M} 1_{\mathrm{f}}$ model, with $\mathrm{P}_{\mathrm{y}}$ (protrusion) applied.

\subsection{Additional Information}

Maximum von Mises stresses in the bone graft block and in compact bone are listed for the $\mathrm{M}_{\mathrm{f}-\mathrm{C}}$ model in Table 4. 
Table 4. Maximum von Mises stresses [N/ $\left.\mathrm{mm}^{2}\right]$; maximum values are given in parentheses.

\begin{tabular}{cccc}
\hline $\mathbf{M} \mathbf{1}_{\mathbf{f}-\mathbf{c}} \mathbf{c}$ Model & $\boldsymbol{\sigma}_{\mathbf{v}, \max }$ Load $\mathbf{F}_{\mathbf{z}}$ & $\boldsymbol{\sigma}_{\mathbf{v}, \max }$ Load $\mathbf{P}_{\mathbf{y}}$ & $\boldsymbol{\sigma}_{\mathbf{v}, \max }$ Load $\mathbf{L}_{\mathbf{x}}$ \\
\hline Compact bone & $11.66\left(17.92^{*}\right)$ & $35.03\left(71.74^{*}\right)$ & $13.79\left(25.14^{*}\right)$ \\
Bone graft & $7.18\left(8.29^{*}\right)$ & $4.80\left(5.66^{*}\right)$ & $1.53^{*}\left(1.79^{*}\right)$ \\
\hline
\end{tabular}

99.9\% p-fractile von Mises stresses [N/ $\left.\mathrm{mm}^{2}\right]$; maximum values are given in parentheses. ${ }^{*}$ : Local stress peak value.

For masticatory force $\mathrm{F}_{\mathrm{z}}$, the maximum von Mises stress is considerably higher in compact bone $\left(17.92 \mathrm{~N} / \mathrm{mm}^{2}\right)$ than in the bone graft $\left(8.29 \mathrm{~N} / \mathrm{mm}^{2}\right)$. High stress values occur in the area of transition between the bone graft block, the augmentation, and the implant. Maximum von Mises stresses for $P_{y}$ and for $L_{x}$ may be regarded as local peak stress values. Neglecting the peak values results in greater von Mises stresses in compact bone $\left(71.74 \mathrm{~N} / \mathrm{mm}^{2}\right.$ for $\mathrm{P}_{\mathrm{y}}$ and $25.14 \mathrm{~N} / \mathrm{mm}^{2}$ for $\left.\mathrm{L}_{\mathrm{x}}\right)$ than in the bone graft block $\left(5.66 \mathrm{~N} / \mathrm{mm}^{2}\right.$ for $\mathrm{P}_{\mathrm{y}}$ and $1.79 \mathrm{~N} / \mathrm{mm}^{2}$ for $\left.\mathrm{L}_{\mathrm{x}}\right)$.

Figure 12 shows equal-scaled von Mises stresses in compact bone and the bone graft block due to masticatory force $\mathrm{F}_{\mathrm{Z}}$ in the $\mathrm{M} 1_{\mathrm{f}-\mathrm{c}}$ model while Figure 13 shows von Mises stresses due to protrusion load $\mathrm{P}_{\mathrm{y}}$ in the same model. Both figures were used to determine the values shown in Table 4 above.
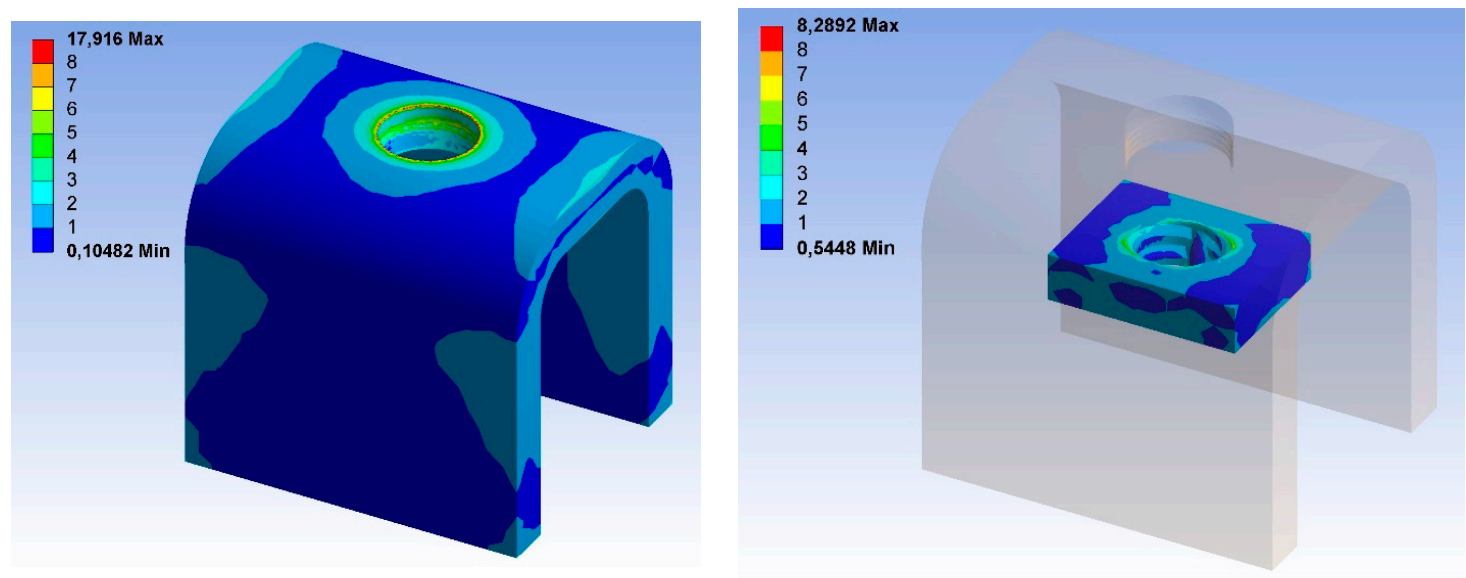

Figure 12. M1f_c model: von Mises stresses [MPa] in compact bone (left) and the bone graft (right), with $\mathrm{F}_{\mathrm{Z}}$ (masticatory force) applied.
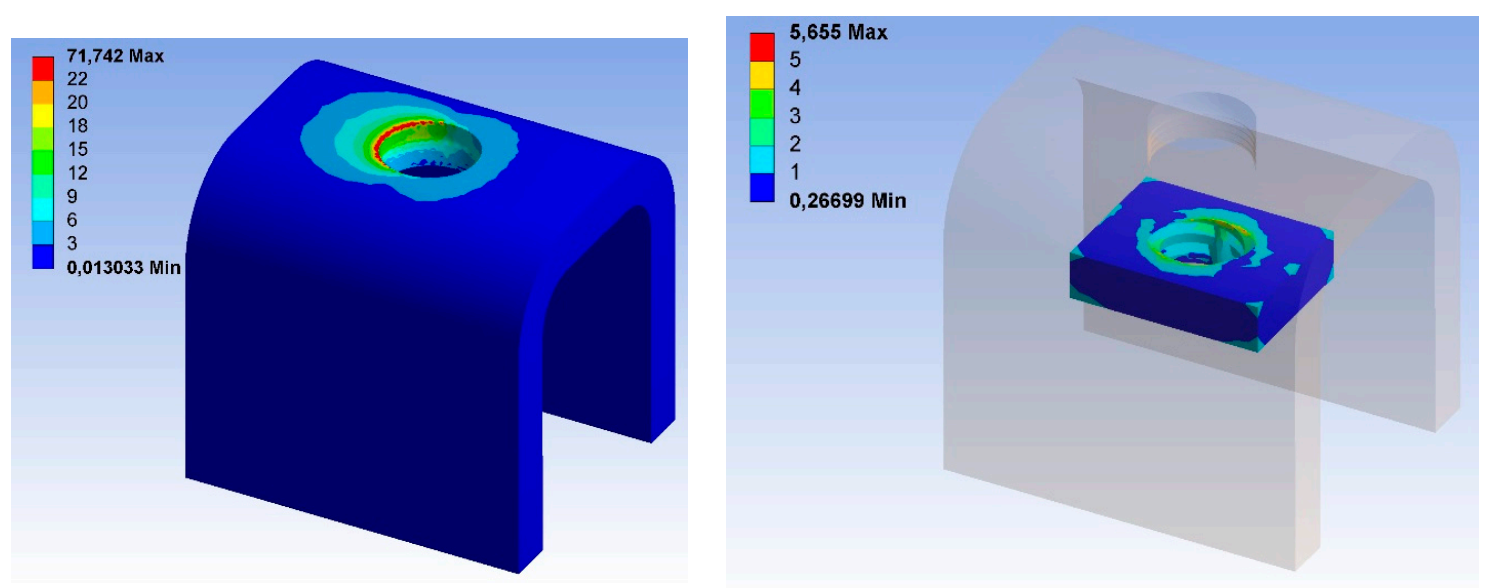

Figure 13. M1f_c model: von Mises stresses [MPa] in compact bone (left) and the bone graft (right), with $\mathrm{P}_{\mathrm{y}}$ (protrusion) applied. 


\section{Discussion}

Performing implantation in areas of the maxilla with small quantities of alveolar bone requires different methods of augmentation. Sinus lift surgery is a common and proven method for this purpose [3,4]. One method of augmentation in the presence of alveolar bone heights below $3 \mathrm{~mm}$, contrary to conventional lateral wall sinus floor elevation, is the introduction of an additional cortical bone graft block $[5,7,17]$ for greater stabilization of the implant.

This study describes the influence of the position of the bone graft block in a simplified U-shaped model and an anatomical model, using different loads, with the aid of the 3D finite-element (FE) method. Cumulative distribution functions (CDF's) are used to interpret the results as well as visualize changes between distributions in the statistical analysis $[5,11,18,19]$.

The finite element method is a common numerical stress analysis in engineering and biomechanics, used to resolve mechanical problems $[1,10,14,20]$. FE models with complex geometric structures can be easily modified to accommodate various assumptions. The quality of the FE model is determined by its concurrence with anatomical and natural conditions [2,11,13,21-23].

One of the debated principles of FE analysis in surgery is the physical properties of bone tissue. Bone tissue is an inhomogeneous material and cannot be defined as easily as titanium. Peterson et al. analyzed the physical behavior of bone tissue in the maxilla [24] by measuring and comparing different areas of the maxilla. Based on Peterson's data, a 3D constitutive law describing the macroscopic mechanical behavior of cortical and trabecular bone was defined [25]. As bone is living tissue, the alteration of its structure over time is very important $[15,16,26,27]$. Changing stress and strain are crucial factors in the healing process after bone fractures or surgery.

The main purpose of this study was to evaluate the ideal biomechanical position of the bone graft block on dental implants used for maxillary sinus floor elevation. Three positions of the bone graft block were used: the lower third, middle, and upper third of the implant. The position closest to compact bone resulted in the lowest von Mises stress distribution within compact bone. This behavior was observed for different model types (patient-specific anatomical model and simplified geometric model) as well as for different load directions and boundary conditions. Therefore, the bone graft block position closest to compact bone in the lower third of the implant is regarded as the best position.

The results indicated three global stress patterns: (1) Stress was highest in cortical bone, lower in the bone graft block, and lowest in the augmented bone (cancellous bone); (2) stresses occurring at off-axial loads were higher in cortical bone and the bone graft block, and lower in augmented bone (cancellous bone) compared with axial loads; (3) high stress concentrations occur at the helical threads of the implant [28]; (4) the high von Mises stresses for protrusive load $\mathrm{P}_{\mathrm{y}}$ occur at the outermost edges between compact bone and implant and should be reduced by adaption of the implant geometry to avoid first bone resorption and then bone-remodeling in these areas.

For masticatory force $\mathrm{F}_{\mathrm{z}}$, von Mises stresses within compact bone were significantly reduced when using a bone graft block compared to the reference model without a bone graft block. The reduction was approximately the same for the bone graft block position in the upper third and the middle of the implant. The reduction of stresses was very pronounced with the bone graft block in the lower third of the implant.

All three bone graft block positions showed the same distribution of accumulated strain energy in which the bone graft block supports the compact bone. This is obvious when the models with a bone graft block are compared to the reference models without a bone graft block.

For protrusive load $\mathrm{P}_{\mathrm{y}}$ and laterotrusive load $\mathrm{L}_{\mathrm{x}}$, only those models with friction contact between the implant and compact bone showed significant differences in respect of von Mises stress distributions. A friction coefficient of 0.3 [9] was simulated for osseointegration as it occurs after implant insertion $[12,29,30]$. Duyck [10] reported no significant difference between higher friction coefficients. Specifically, the lowest position of the bone graft block resulted in the lowest stress distribution. There was no significant difference in the stress distribution of the bone graft block position in bonded contact models loaded with $\mathrm{P}_{\mathrm{y}}$ and $\mathrm{L}_{\mathrm{x}}$. Even models with and without bone graft 
blocks showed no significant difference in regard of bonded contact. On the other hand, evaluating the strain energy of the individual parts shows that the bone graft block participates in load transfer to the greatest extent in the lower position and discharges maximum energy to compact bone by reducing its strain energy.

The 3D patient-specific anatomical model (M2) with geometric and natural irregularities from CT data is similar to the simplified U-shaped model (M1) for masticatory force $F_{z}$. Therefore, a simplified model is advisable for exploring the optimal bone graft block position in general. Complex patient-specific 3D FE models with a large number of nodes are not necessary to assess implants in the distal region of the maxilla. Simple models with fewer nodes can be analyzed and compared easily with the same outcome as anatomical models [6].

Acknowledgments: The project was supported by the Austrian Science Fund FWF L526-B05 and by the RISE Project R-09/03/003-SCH at Paracelsus Medical University, Salzburg, Austria. The study was approved by the Ethics Committee of Salzburg (Ethikkommission für das Bundesland Salzburg), Approval No. 415-E803/3-2007. The authors thank Bredent Medical Company for their support in regard of implant CAD data.

Author Contributions: Peter Schuller-Götzburg and Franz Watzinger both medical group leaders conceived of the presented idea. Thomas Forte and Werner Pomwenger performed the FE-simulations and result presentation. Alexander Petutschnigg and Karl Entacher are responsible for verification of the analytical methods and result interpretation. Paper writing was carried out by Peter Schuller-Götzburg, Karl Entacher and Alexander Petutschnigg.

Conflicts of Interest: The authors declare no conflict of interest.

\section{References}

1. Poelert, S.; Valstar, E.; Weinans, H.; Zadpoor, A.A. Patient-specific finite element modeling of bones. Proc. Inst. Mech. Eng. H 2013, 227, 464-478. [CrossRef] [PubMed]

2. Zimmermann, R.; Seitz, S.; Vargas, L. The use of virtual models to estimate the amount of grafting material: A case study. Int. J. Oral Maxillofac. Implants 2015, 30, e43-e44. [CrossRef] [PubMed]

3. Boyne, P.J.; James, R.A. Grafting of the maxillary sinus floor with autogenous marrow and bone. J. Oral Surg. 1980, 38, 613-616. [PubMed]

4. Guerrero, J.S.; Al-Jandan, B.A. Lateral wall sinus floor elevation for implant placement: Revisiting fundamentals and the surgical technique. J. Calif. Dent. Assoc. 2013, 41, 185-195. [PubMed]

5. Schuller-Götzburg, P.; Entacher, K.; Petutschnigg, A.; Pomwenger, W.; Watzinger, F. Sinus lift with cortical bone graft block: A patient-specific 3D-finite element study. Int. J. Oral Maxillofac. Implants 2012, 27, 359-368. [PubMed]

6. Yan, X.; Zhang, X.; Chi, W.; Ai, H.; Wu, L. Comparing the influence of crestal cortical bone and sinus floor cortical bone in posterior maxilla bi-cortical dental implantation: A three-dimensional finite element analysis. Acta Odontol. Scand. 2015, 73, 312-320. [CrossRef] [PubMed]

7. Khoury, F. Augmentation of the sinus floor with mandibular bone block and simultaneous implantation: A 6-year clinical investigation. Int. J. Oral Maxillofac. Implants 1999, 14, 557-564. [PubMed]

8. Joda, T.; Bragger, U.; Gallucci, G. Systematic literature review of digital three-dimensional superimposition techniques to create virtual dental patients. Int. J. Oral Maxillofac. Implants 2015, 30, 330-337. [CrossRef] [PubMed]

9. Lin, C.L.; Chang, S.H.; Chang, W.J.; Kuo, Y.C. Factorial analysis of variables influencing mechanical characteristics of a single tooth implant placed in the maxilla using finite element analysis and the statistics-based taguchi method. Eur. J. Oral Sci. 2007, 115, 408-416. [CrossRef] [PubMed]

10. Duyck, J.; Van Oosterwyck, D.J.; De Cooman, H.; Puers, M.; Vander Sloten, R.; Naert, I. Three-dimensional force measurements on oral implants: A methodological study. J. Oral Rehabilit. 2000, 27, 744-753. [CrossRef]

11. Tepper, G.; Haas, R.; Zechner, W.; Krach, W.; Watzek, G. Three-dimensional finite element analysis of implant stability in the atrophic posterior maxilla: A mathematical study of the sinus floor augmentation. Clin. Oral Implants Res. 2002, 13, 657-665. [CrossRef] [PubMed]

12. Grant, J.A.; Bishop, N.E.; Götzen, N.; Sprecher, C.; Honl, M.; Morlock, M.M. Artificial composite as a model of human trabecular bone: The implant-bone interface. J. Biomech. 2007, 40, 1158-1164. [CrossRef] [PubMed] 
13. Fanuscu, M.I.; Vu, H.V.; Poncelet, B. Implant biomechanics in grafted sinus: A finite element analysis. J. Oral Implantol. 2004, 30, 59-68. [CrossRef] [PubMed]

14. Mericske-Stern, R.; Venetz, E.; Fahrlander, F.; Burgin, W. In vivo force measurements on maxillary implants supporting a fixed prosthesis or an overdenture: A pilot study. J. Prosthet. Dent. 2000, 84, 535-547. [CrossRef] [PubMed]

15. Wolf, J. Das Gesetz der Transformation der Knochen-1892; Reprint; Pro Business: Berlin, Germany, 2010.

16. Frost, H.M. From Wolff's law to the Utah paradigm: Insights about bone physiology and its clinical applications. Anat. Rec. 2001, 262, 398-419. [CrossRef] [PubMed]

17. Jensen, O.T.; Shulman, L.B.; Block, M.S.; Iacono, V.J. Report of the Sinus Consensus Conference of 1996. Int. J. Oral Maxillofac. Implants 1998, 13,11-45. [PubMed]

18. Pesqueria, A.; Goiato, M.; Gennari-Filho, H.; Monteiro, D.; Dos Santos, D.; Haddad, M.; Pellizzer, E. The use of stress analysis methods to evaluate the biomechanics of oral rehabilitation with implants. J. Oral Implantol. 2012, 40, 217-228. [CrossRef] [PubMed]

19. Himmlová, L.; Dostálová, T.; Kácovsky, A.; Konvicková, S. Influence of implant length and diameter on stress distribution: A finite element analysis. J. Prosthet. Dent. 2004, 91, 20-25. [CrossRef] [PubMed]

20. Koca, O.L.; Eskitascioglu, G.; Usumez, A. Three-dimensional finite-element analysis of functional stresses in different bone locations produced by implants placed in the maxillary posterior region of the sinus floor. J. Prosthet. Dent. 2005, 93, 38-44. [CrossRef] [PubMed]

21. Okumura, N.; Stegaroiu, R.; Kitamura, E.; Kurokawa, K.; Nomura, S. Influence of maxillary cortical bone thickness, implant design and implant diameter on stress around implants: A three-dimensional finite element analysis. J. Prosthodont. Res. 2010, 54, 133-142. [CrossRef] [PubMed]

22. Van Staden, R.C.; Guan, H.; Loo, Y.C. Application of the finite element method in dental implant research. Comput. Methods Biomech. Biomed. Eng. 2006, 9, 257-270. [CrossRef] [PubMed]

23. Li, T.; Yang, X.; Zhang, D.; Zhou, H.; Shao, J.; Ding, Y.; Kong, L. Analysis of the biomechanical feasibility of a wide implant in moderately atrophic maxillary sinus region with finite element method. Oral Surg. Oral Med. Oral Pathol. Oral Radiol. 2012, 114, e1-e8. [CrossRef] [PubMed]

24. Peterson, J.; Wang, Q.; Dechow, P.C. Material properties of the dentate maxilla. Anat. Rec. A Discov. Mol. Cell. Evolut. Biol. 2006, 288, 962-972. [CrossRef] [PubMed]

25. Garcia, D.; Zysset, P.K.; Charlebois, M.; Curnier, A. A three-dimensional elastic plastic damage constitutive law for bone tissue. Biomech. Model. Mechanobiol. 2009, 8, 149-165. [CrossRef] [PubMed]

26. Mullender, M.G.; Huiskes, R. Proposal for the regulatory mechanism of Wolff's law. J. Orthop. Res. 1995, 13, 503-512. [CrossRef] [PubMed]

27. Shanbhag, S.; Shanbhag, V.; Stavropoulos, A. Volume changes of maxillary sinus augmentations over time: A systematic review. Int. J. Oral Maxillofac. Implants 2014, 29, 881-892. [CrossRef] [PubMed]

28. Schuller-Götzburg, P.; Krenkel, C.; Reiter, T.J.; Plenk, H. 2D-finite element analyses and histomorphology of lag screws with and without a biconcave washer. J. Biomech. 1999, 32, 511-520. [CrossRef]

29. Ding, X.; Zhu, X.H.; Liao, S.H.; Zhang, X.H.; Chen, H. Implant-bone interface stress distribution in immediately loaded implants of different diameters: A three-dimensional finite element analysis. J. Prosthodont. 2009, 18, 393-402. [CrossRef] [PubMed]

30. Goiato, M.C.; Bannwart, L.C.; Pesqueria, A.A.; Santos, D.M.; Haddad, M.F.; Santos, M.R.; Castilho, P.U. Immediate loading of overdentures: Systematic review. Oral Maxillofac. Surg. 2014, 18, 259-264. [CrossRef] [PubMed]

(C) 2018 by the authors. Licensee MDPI, Basel, Switzerland. This article is an open access article distributed under the terms and conditions of the Creative Commons Attribution (CC BY) license (http:// creativecommons.org/licenses/by/4.0/). 